\title{
Multi-Agent Bilateral Bargaining AND THE Nash Bargaining Solution
}

by

Sang-Chul Suh and Quan Wen

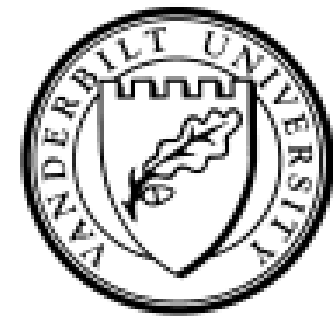

Working Paper No. 03-W06

March 2003

DEPARTMENT OF ECONOMICS

VANDERBILT UNIVERSITY

NASHVILLE, TN 37235

www.vanderbilt.edu/econ 


\title{
Multi-Agent Bilateral Bargaining and the Nash Bargaining Solution*
}

\author{
Sang-Chul Suh ${ }^{\dagger}$ \\ University of Windsor
}

\author{
Quan Wen \\ Vanderbilt University
}

March 2003

\begin{abstract}
This paper studies a bargaining model where $n$ players play a sequence of $(n-1)$ bilateral bargaining sessions. In each bilateral bargaining session, two players follow the same bargaining process as in Rubinstein's (1982). A partial agreement between two players is reached in the session and one player effectively leaves the game with a share agreed upon in the partial agreement and the other moves on to the next session. Such a (multi-agent) bilateral bargaining model admits a unique subgame perfect equilibrium. Depending on who exits and who stays, we consider two bargaining procedures. The equilibrium outcomes under the two bargaining procedures converge to the Nash (1950) bargaining solution of the corresponding bargaining problem as the players' discount factor goes to one. Thus, the bilateral bargaining model studied in this paper provides a non-cooperative foundation for the Nash cooperative bargaining solution in the multilateral case.
\end{abstract}

JEL Numbers: C72, C78

Keywords: Multilateral bargaining, subgame perfect equilibrium, Nash bargaining solution.

\footnotetext{
*We would like to thank John Conlon for his comments. We gratefully acknowledge financial support from the Social Sciences and Humanities Research Council of Canada.

${ }^{\dagger}$ Department of Economics, University of Windsor, Windsor, Ontario, N9B 3P4, Canada. E-mail: scsuh@uwindsor.ca.

${ }_{\ddagger}^{\ddagger}$ Department of Economics, Vanderbilt University, VU Station B \#351819, 2301 Vanderbilt Place, Nashville, TN 37235-1819, U.S.A. Email: quan.wen@vanderbilt.edu.
} 


\section{Introduction}

A bargaining problem deals with a situation where some players negotiate over sharing a fixed sum of resources. There are two approaches to analyzing a bargaining problem, namely the cooperative approach and the non-cooperative approach. One well-known and widely adopted cooperative bargaining solution is the Nash (1950) bargaining solution. An equally popular and important non-cooperative bargaining solution is the subgame perfect equilibrium in Rubinstein's (1982) bilateral bargaining model. Binmore (1987) first established the following linkage of Nash's solution with Rubinstein's solution in the bilateral case: Rubinstein's non-cooperative bargaining solution converges to the Nash cooperative bargaining solution as players' discount factor goes to one. Generalizing Binmore's result to the multilateral case has been less successful since many extensions of Rubinstein's model to the multilateral case admit multiple subgame perfect equilibrium outcomes. For example, the models by Herrero (1985), Sutton (1986) and Haller (1986) reduce to the Rubinstein model in the bilateral case, yet admit multiple subgame perfect equilibrium outcomes in the multilateral case. ${ }^{1}$ When partial agreements are possible, the multilateral bargaining models of Chae and Yang $(1988,1990,1994)$, Krishna and Serrano (1996) and Jun (1987) restore the uniqueness of the subgame perfect equilibrium. ${ }^{2}$

This paper studies a (multi-agent) bilateral bargaining model to analyze multilateral bargaining problems. The bilateral bargaining model consists of a finite number of players and a finite sequence of bargaining sessions where a pair of players bargain as in Rubinstein's model. Due to the simplicity of Rubinstein's bilateral bargaining model and the finiteness of bilateral bargaining sessions, there is a unique subgame perfect equilibrium for any given bargaining procedure. We analyze two bargaining procedures in this paper and show that as players' discount factor goes to one, the subgame perfect equilibrium outcomes converge to the Nash bargaining solution in the corresponding bargaining problem. Therefore, the

\footnotetext{
${ }^{1}$ Also refer to Osborne and Rubinstein (1990) and Muthoo (1999) on related issues.

${ }^{2}$ Refer to Cai (2000) for the issue of multiple equilibria and inefficiency in a multi-agent bargaining model.
} 
bilateral bargaining model provides a non-cooperative foundation for the Nash cooperative bargaining solution in the multilateral case. The bilateral bargaining model reduces to Rubinstein's model in the bilateral case, thus this paper generalizes Binmore (1987) to the multilateral case.

The bilateral bargaining model is motivated by a number of practical considerations. There are certainly many important factors in multilateral bargaining problems. One arguably important factor is the possibility of communication among all the players. In many situations, it may be impossible or too costly for all the players to negotiate at the same time and at the same place. For example, during bargaining among a producer, a wholesaler and a retailer, the three parties may not meet at the same time and place to negotiate the wholesale price and retail price. Instead, the negotiation could be conducted by two separate bilateral bargaining sessions as in the bilateral bargaining model. The two bilateral bargaining sessions determine the wholesale price and retail price respectively.

The bilateral bargaining model has many advantages over the other multilateral bargaining models, including its simplicity and strong predictability. The equilibrium outcome crucially depends upon the bargaining procedure in the model. A bargaining procedure specifies who leaves the game and who makes the initial offer in every bilateral bargaining session. For any given bargaining procedure, the equilibrium outcome is derived from backward induction. For example, in a three-player bargaining problem with a linear bargaining frontier, under the procedure that players 1 and 2 bargain in the first session (player 1 leaves the game after the first session) and players 2 and 3 bargain in the second session, the players' final payoffs in the unique subgame perfect equilibrium are

$$
\left(\frac{1}{1+\delta}, \frac{\delta}{(1+\delta)^{2}}, \frac{\delta^{2}}{(1+\delta)^{2}}\right)
$$

which converge to $(1 / 2,1 / 4,1 / 4)$ as the players' discount factor $\delta$ goes to one. The Nash bargaining solution in this case is, however, $(1 / 3,1 / 3,1 / 3)$. The discrepancy between the two solutions is due to the advantage for player 1 of being able to leave the game which does not disappear as $\delta$ goes to one. 
But the two bargaining procedures we consider in this paper do not allow any one player to have any advantage over others as $\delta$ goes to one. Let us consider the two procedures in three player models.

In the first bargaining procedure, the proposer proposes to "offer" a certain sum to the responder. If the responder accepts the proposal, then the current bargaining session ends, the responder exits the game with the share offered and the proposer moves on to the next session to bargain with a new player. If the responder rejects the proposal, then the game proceeds to the next bargaining period where the current responder becomes the proposer and the proposer becomes the responder. For example, in the first session player 1 makes an offer. If player 2 accepts, then player 2 leaves and player 1 bargains with player 3 . If player 2 rejects, then player 2 makes a counteroffer. If player 1 accepts, then player 1 leaves, and so on. The players' payoffs in the unique subgame perfect equilibrium are

$$
\left(\frac{1}{1+2 \delta}, \frac{\delta}{1+2 \delta}, \frac{\delta}{1+2 \delta}\right)
$$

In the second bargaining procedure, the proposer proposes to "demand" a certain amount. If the responder accepts the proposal, then the current bargaining session ends with the accepted proposal as the partial agreement of the session, the proposer exits the game and the responder moves on to the next session to bargain with a new player. If the responder rejects the proposal, then the game proceeds to the next bargaining period where the current responder becomes the proposer and the proposer becomes the responder. The players' payoffs in the unique subgame perfect equilibrium are

$$
\left(\frac{1}{1+\delta+\delta^{2}}, \frac{\delta}{1+\delta+\delta^{2}}, \frac{\delta^{2}}{1+\delta+\delta^{2}}\right)
$$

Both (1) and (2) converge to the Nash bargaining solution $(1 / 3,1 / 3,1 / 3)$ as $\delta$ goes to one. We will show that the same is true for a general number of players so that the bilateral bargaining model can be viewed as a non-cooperative foundation of the Nash bargaining solution in the multilateral case. 
In the case of a linear bargaining frontier, Asheim (1992) obtains (2) as the unique equilibrium outcome under a stronger equilibrium concept. Chatterjee and Sabourian (1998) investigate the strategic complexity in multilateral bargaining and show that (2) is the only subgame perfect equilibrium outcome that satisfies their complexity criterion. Solution (1) is also obtained by Chae and Yang (1988, 1994), and Krishna and Serrano (1996) in the case of a linear bargaining frontier. However, the bilateral model has a different equilibrium outcome than those models in the case of a non-linear bargaining frontier.

The rest of the paper is organized as follows. We first introduce the bilateral bargaining model in Section 2, then investigate two subgame perfect equilibrium outcomes under two bargaining procedures in Sections 3 and 4 respectively. Section 5 is devoted to establishing the linkage of the two equilibrium outcomes with the Nash bargaining solution. Section 6 concludes the paper.

\section{The Model}

A finite number of players, called players $1,2, \ldots, n$, negotiate how to split a pie of size 1 via $(n-1)$ bilateral bargaining sessions. In each bilateral bargaining session, two players negotiate a partial and bilateral agreement that specifies the share of the pie for one of the players who then leaves the game. After a partial agreement, the other player continues to negotiate with the rest of the players over the remainder of the pie. The $(n-1)$ bilateral bargaining sessions determine $(n-1)$ players' shares of the pie and hence all $n$ players' shares of the pie.

Each bilateral bargaining session follows Rubinstein's (1982) bilateral bargaining framework. In each period of a session, one player (the proposer) makes a proposal and another player (the responder) either accepts or rejects the proposal. We consider two bargaining models depending on proposal types: In the first, the proposer proposes to "demand" and in the second, the proposer proposes to "offer." In the first case, if the responder accepts the proposer's proposal, then the current bargaining session ends with the accepted proposal as 
the partial agreement of the session, the proposer exits the game and the responder moves on to the next session to bargain with a new player. In the second case, if the responder accepts the proposer's proposal, then the current bargaining session ends with the accepted proposal as the partial agreement of the session, the responder exits the game with the share offered by the proposer and the proposer moves on to the next session to bargain with a new player. If the responder rejects then the game proceeds to the next bargaining period in the same session where the current responder becomes the proposer and the proposer becomes the responder. In both cases, the partial agreement is reflected on the amounts to be bargained over in the following sessions.

Without a loss of generality, assume players are named so that player 1 bargains with player 2 in the first bargaining session, then either player 1 or player 2 bargains with player 3 in the second bargaining session, and so on.

The outcome of the bilateral bargaining game is given by $(n-1)$ partial agreements, denoted by

$$
\pi=\left(x_{1}, t_{1}, x_{2}, t_{2}, \cdots, x_{n}, t_{n}\right)
$$

where $t_{i}$ is the period where player $i$ agrees to leave the game with his share $x_{i}$ of the pie. The game structure of the bilateral bargaining model imposes certain conditions on $t_{1}, \cdots, t_{n}$. For example, suppose player $i$ and player $j$ bargain in the $(j-1)$-th session for $i<j$, then $t_{i} \geq t_{i^{\prime}}$ and $t_{j} \geq t_{i^{\prime}}$ for all $i^{\prime} \neq i$ and $i^{\prime}<j$. This implies that if player $i$ and player $j$ fail to reach a partial agreement, then $t_{i}=t_{j^{\prime}}=\infty$ for all $j^{\prime} \geq j$. Player $i$ 's payoff from outcome $\pi$ is $\delta_{i}^{t_{i}-1} u_{i}\left(x_{i}\right)$ where $\delta_{i}$ is player $i$ 's discount factor per bargaining period and $u_{i}(\cdot)$ is player $i$ 's utility function which is assumed to be concave and continuously differentiable. We assume that there is no discounting between two consecutive bargaining sessions. That is, a bargaining session starts immediately after a partial agreement. Adding a discount between sessions would not change the nature of the model but simply rescale players' payoffs. In the case where two players fail to reach a partial agreement, all the remaining players would have a payoff of zero, provided by the discounting. 
Histories and strategies are defined in the usual way. A history summarizes all the actions played in the past and a strategy profile specifies an appropriate action for an appropriate player, a proposal by the proposer and a reaction by the responder, for every possible finite history. Any strategy profile induces a unique outcome path and players evaluate their strategies based on their payoffs from the outcome path induced by the strategy profile. In this paper, we study the subgame perfect equilibrium derived from imposing the requirement of Nash equilibrium in any subgame. Depending on the type of proposal in every period, there are many possible bargaining procedures. As we mentioned at the beginning of this section, we analyze two of them in detail since they have traceable structures that enable us to characterize their unique subgame perfect equilibrium outcomes. The first procedure specifies that the proposer "offers." The second procedure specifies that the proposer "demands". In Section 5, we will describe the corresponding cooperative bargaining problem, the Nash bargaining solution and its consistency before we prove that the limit of the subgame perfect equilibrium outcomes of Sections 3 and 4 converge to the Nash bargaining solution.

\section{The Proposer "Offers"}

In this case, the proposer starts a bargaining session by offering a certain sum to the responder. If the responder accepts the proposal, she exits the game with the sum, which will be distributed when all of the bargaining sessions are completed, and the proposer moves on to the next session with the partial agreements made in previous sessions. The game proceeds as follows: Player 1 and player 2 bargain in the first session. If player 2 accepts an offer, then player 2 leaves the game and player 1 bargains with player 3 in the second session, and vice versa. This procedure continues in this fashion for all of the remaining sessions. The

following Figure 1 describes the $(j-1)$-th bilateral bargaining session between player $i$ and player $j$ for $i<j$ : 


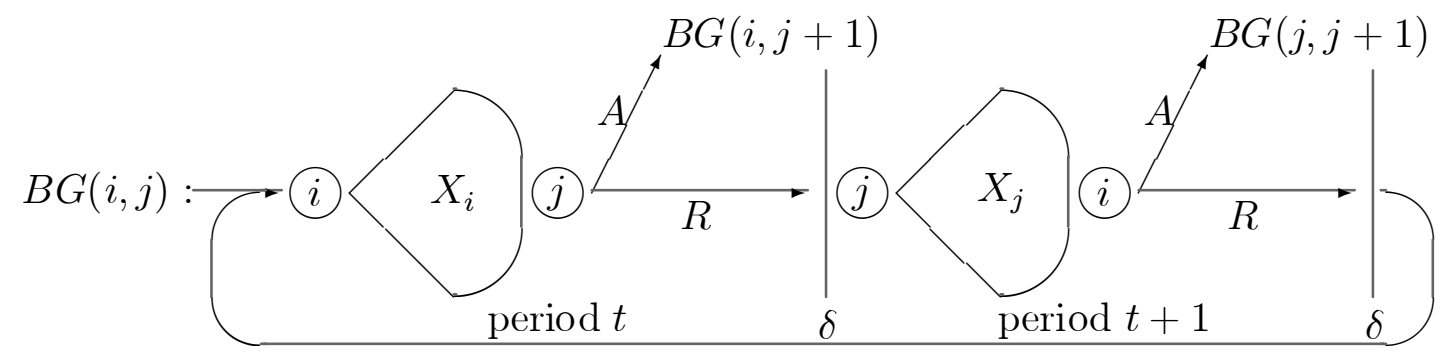

FiguRE 1. The $(j-1)$-th session where the responder receives an offer to leave the game with a certain level of his share.

The bilateral bargaining game has $(n-1)$ bilateral bargaining sessions and is solvable by backward induction. The last bargaining session is the same as Rubinstein's model where the total surplus to be allocated is the remainder of the pie given by the $(n-2)$ partial agreement from the first $(n-2)$ sessions. Since the payoff vector is uniquely determined in the subgame at the last session, the payoff to a proposer in the second to the last session is also uniquely determined by the $(n-3)$ partial agreements from the first $(n-3)$ sessions, and so on. Given the unique subgame perfect equilibrium outcome in the last session, there is a unique subgame perfect equilibrium outcome in the second to the last session. By backward induction, there is a unique subgame perfect equilibrium outcome in the entire game. This argument is made formally in the following Proposition 1:

Proposition 1 In the game where the responder receives an offer to leave the game in every period, the bilateral bargaining model has a unique subgame perfect equilibrium that is efficient. The equilibrium outcome is determined recursively by (5) and (6) below.

Proof: Denote player $i$ 's offer to his opponent player in a generic bilateral bargaining session by $X_{i}$. First consider the last bargaining session where there are only two players in the game, say players $i$ and $n$ (note that player $n$ must in the last bargaining session). Suppose the history is such that the total share to the other $(n-2)$ players is $Y$. Since the last bargaining 
session is the same as Rubinstein's (1982) model where the total size of the pie is $1-Y$, the last bargaining session has a unique subgame perfect equilibrium. In the equilibrium, player $i$ offers $X_{i}$ and accepts $X_{n}$, and player $n$ offers $X_{n}$ and accepts $X_{i}$, where $X_{i}$ and $X_{n}$ satisfy the following two conditions:

$$
\begin{aligned}
& u_{n}\left(X_{i}\right)=\delta_{n} u_{n}\left(1-Y-X_{n}\right), \\
& u_{i}\left(X_{n}\right)=\delta_{i} u_{i}\left(1-Y-X_{i}\right) .
\end{aligned}
$$

(3) asserts that player $n$ is indifferent between accepting player $i$ 's offer in the current period and collecting $1-Y-X_{n}$ in the following period. (4) states the same equilibrium condition for player $i$. The equilibrium outcome in the last session is that player $n$ accepts $X_{i}$ immediately so (3) and (4) determine the two players' payoffs in the equilibrium. Player $i$ 's share depends on $\delta_{i}, \delta_{n}$ and $Y$; denote it as

$$
s_{i}^{n-1}(Y)=1-Y-X_{i}
$$

and player $n$ 's share is simply $X_{i}$.

Now consider the $(j-1)$-th bargaining session between player $i$ and player $j$ where the total share to the $(j-2)$ players who have agreed to leave is $Y$. For either player in the current session, if a player's offer is accepted then he moves to the following session and his share of the pie is uniquely determined by the unique subgame perfect equilibrium outcome for the rest of the game. For player $i$ or $j$, denote the share of player $i$ as $s_{i}^{j}\left(Y+X_{i}\right)$ where $1-Y-X_{i}$ is the remaining size of the pie at the beginning of the $j$-th bargaining session. More specifically, if player $i$ offers $X_{i}$ and player $j$ accepts then player $i$ 's share is $s_{i}^{j}\left(Y+X_{i}\right)$, while player $j$ 's share is $X_{i}$. If player $j$ offers $X_{j}$ and player $i$ accepts, then player $i$ 's share is $X_{j}$ and player $j$ 's share is $s_{j}^{j}\left(Y+X_{j}\right)$. From Shaked and Sutton (1984), it is straightforward to show that there is a unique pair of equilibrium offers in the current bargaining session. Player $i$ offers $X_{i}$ and accepts $X_{j}$, and player $j$ offers $X_{j}$ and accepts $X_{i}$, where

$$
\begin{aligned}
& u_{j}\left(X_{i}\right)=\delta_{j} u_{j}\left(s_{j}^{j}\left(Y+X_{j}\right)\right), \\
& u_{i}\left(X_{j}\right)=\delta_{i} u_{i}\left(s_{i}^{j}\left(Y+X_{i}\right)\right) .
\end{aligned}
$$


(5) asserts that player $j$ is indifferent between accepting $X_{i}$ in the current period and collecting $s_{j}^{j}\left(Y+X_{j}\right)$ in the following period, while (6) states the same condition for player $i$. Player $j$ accepts $X_{i}$ immediately so player $i$ 's share is

$$
s_{i}^{j-1}(Y)=s_{i}^{j}\left(Y+X_{i}\right)
$$

and player $j$ 's share is $X_{i}$.

By backwards induction, the bilateral bargaining game under this procedure has a unique subgame perfect equilibrium. In the equilibrium, player 1 will make acceptable offers to the other players sequentially in the first period, which yields an efficient outcome. Q.E.D.

The equilibrium outcome of Proposition 1 is calculated recursively, which is different from the simultaneous equation system in Chae and Yang $(1992,1994)$, and Krishna and Serrano (1996). If all the players have the same discount factor and linear utility function, however, then the bilateral bargaining model has the same equilibrium outcomes as theirs.

Proposition 2 Suppose that all the players have the same discount factor $\delta$ and linear utility function. In the game where the responder receives an offer to leave the game in every period, players' shares in the unique subgame perfect equilibrium are

$$
\left(\frac{1}{1+(n-1) \delta}, \frac{\delta}{1+(n-1) \delta}, \ldots, \frac{\delta}{1+(n-1) \delta}\right) \text {. }
$$

The proof of Proposition 2 follows standard backwards induction. It is omitted here but available from the authors upon request. In this case, we have

$$
s_{i}^{j}(Y)=\frac{1}{1+(n-j) \delta}(1-Y)
$$

Proposition 2 suggests that the subgame perfect equilibrium outcome converges to the Nash bargaining solution $(1 / n, \cdots, 1 / n)$ as $\delta$ goes to one. We will establish this property for the general case in Section 5 . 


\section{The Proposer "Demands"}

Parallel to the previous section, this section considers the model where the proposer demands. If the responder accepts the proposal, then the proposer exits the game and the responder moves on to the next session. The game proceeds as follows: players 1 and 2 bargain in the first session. If player 1's demand is accepted then player 1 leaves the game and player 2 bargains with player 3 in the second bargaining session. If player 2's demand is accepted then player 2 leaves the game and player 1 bargains with player 3 in the second bargaining session. This procedure continues in this fashion for the remaining sessions. The following Figure 2 describes the $(j-1)$-th bilateral bargaining session between player $i$ and player $j$ for $i<j$ :

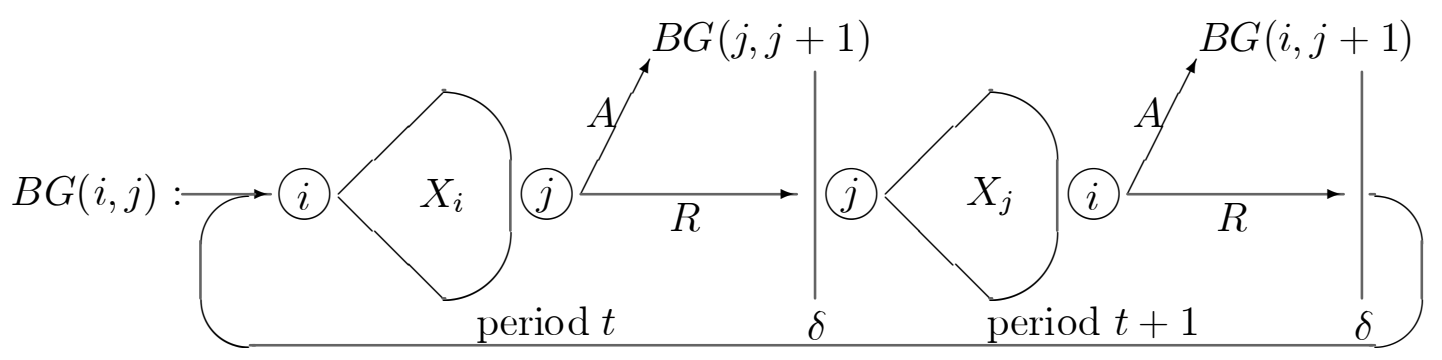

Figure 2. The $(j-1)$-th session when the proposer demands to leave.

Similar to the case where the responder receives an offer to leave, the bilateral bargaining model when the proposer demands to leave has a unique subgame perfect equilibrium.

Proposition 3 When the proposer demands to leave, the bilateral bargaining model has a unique subgame perfect equilibrium that is efficient. The equilibrium outcome is determined recursively by (9) and (10) below.

Proof: In this proof we denote player $i$ 's demand as $X_{i}$. First consider a subgame in the last bargaining session between player $i$ and player $n$ for $i<n$ where the total share to the other 
$(n-2)$ players is $Y$. This bilateral bargaining session is the same as Rubinstein's (1982) model with a pie of size $1-Y$, so it is a unique perfect equilibrium outcome. The equilibrium outcome is given by players' demands, $X_{i}$ and $X_{n}$. The equilibrium conditions for $X_{i}$ and $X_{n}$ are that the responder is indifferent between accepting and rejecting the standing offer:

$$
\begin{aligned}
& u_{n}\left(1-Y-X_{i}\right)=\delta_{n} u_{n}\left(X_{n}\right) \\
& u_{i}\left(1-Y-X_{n}\right)=\delta_{i} u_{i}\left(X_{i}\right) .
\end{aligned}
$$

Player $i$ 's share of the pie is then given by $s_{i}^{n}(Y)=X_{i}$.

Now consider the $(j-1)$-th bilateral bargaining session between players $i$ and $j$ for $i<j$ where the total share to the $(j-2)$ players who have left the game is $Y$. If player $i$ demands $X_{i}$ and player $j$ accepts, then player $i$ 's share is $X_{i}$ and player $j$ 's share is given by $s_{j}^{j}\left(Y+X_{i}\right)$ for the rest of the game. If player $j$ demands $X_{j}$ and player $i$ accepts, then player $j$ 's share is $X_{j}$ and player $i$ 's share is given by $s_{i}^{j}\left(Y+X_{j}\right)$. Again, Shaked and Sutton's (1984) argument implies that there is a unique pair of equilibrium demands that satisfies the following conditions:

$$
\begin{aligned}
& u_{j}\left(s_{j}^{j}\left(Y+X_{i}\right)\right)=\delta_{j} u_{j}\left(X_{j}\right), \\
& u_{i}\left(s_{i}^{j}\left(Y+X_{j}\right)\right)=\delta_{i} u_{i}\left(X_{i}\right) .
\end{aligned}
$$

(9) asserts that player $j$ is indifferent between accepting player $i$ 's demand $X_{i}$ after which his share is $s_{j}^{j}\left(Y+X_{i}\right)$, and rejecting player $i$ 's demand and collecting $X_{j}$ in the following period. (10) states the same condition for player $i$. The equilibrium outcome in such a subgame is that player $j$ accepts player $i$ 's demand $X_{i}$ immediately so that player $i$ 's share is given by

$$
s_{i}^{j-1}(1-Y)=X_{i}
$$

By backwards induction, the bilateral bargaining model then has a unique subgame perfect equilibrium.

Q.E.D.

In the subgame perfect equilibrium of Proposition 3, player 2 accepts player 1's demand, then player 3 accepts player 2's demand and so on, ending with player $n$ accepting player 
$(n-1)$ 's demand. When all the players have a common discount factor $\delta$ and linear utility, we can solve the equilibrium outcome of Proposition 3.

Proposition 4 Suppose that all the players have the same discount factor $\delta$ and linear utility function. When the proposer demands to leave in any period, players' payoffs (or shares) in the unique subgame perfect equilibrium are

$$
\left(\frac{1}{1+\delta+\delta^{2}+\ldots \delta^{n-1}}, \frac{\delta}{1+\delta+\delta^{2}+\ldots \delta^{n-1}}, \ldots, \frac{\delta^{n-1}}{1+\delta+\delta^{2}+\ldots \delta^{n-1}},\right)
$$

The proof of Proposition 4 is omitted and is available from the authors upon request. In this case,

$$
s_{i}^{j}(Y)=\frac{1}{1+\delta+\cdots+\delta^{n-j}} Y .
$$

Note that the equilibrium outcome of Proposition 4 also converges to the Nash bargaining solution $(1 / n, 1 / n, \cdots, 1 / n)$ and it's bargaining frontier is linear.

\section{Consistency and the Nash Bargaining Solution}

In this section, we establish the linkage between our non-cooperative bargaining solutions and the Nash cooperative bargaining solution in a general $n$-player bargaining game. Krishna and Serrano (1996) motivated their bargaining model along the consistency principle of the Nash bargaining solution. The consistency principle requires a solution to respond "consistently" to games (or reduced games) with varying numbers of players. In Krishna and Serrano (1996), the player who accepts any proposal exits the game, as motivated in the consistency principle, and the other players continue to negotiate in the reduced game in a similar fashion. It is straightforward to show that the Nash bargaining solution is consistent. By the consistency of the Nash bargaining solution, we are able to show that the two subgame perfect equilibrium outcomes we derived in the bilateral bargaining model converge to the symmetric Nash bargaining solution in the corresponding cooperative bargaining problem, as players' common discount factor goes to 1 . 
For a non-cooperative bilateral bargaining game, the corresponding cooperative bargaining problem is described by $\langle A, d\rangle$, where $A$ is the set of all possible payoff vectors under agreement and $d$ is the disagreement payoff vector, where

$$
A=\left\{\left(u_{1}\left(x_{1}\right), u_{2}\left(x_{2}\right), \ldots, u_{n}\left(x_{n}\right)\right) \mid \sum_{i=1}^{n} x_{i} \leq 1, x_{i} \geq 0 \forall i=1, \cdots, n .\right\},
$$

and $d=\left(u_{1}(0), u_{2}(0), \ldots, u_{n}(0)\right)=0$ without loss of generality. The concavity of players' payoff functions ensures the convexity of set $A$. The symmetric Nash (1950) bargaining solution to the cooperative bargaining problem $\langle A, d\rangle$ is characterized by the solution to the following optimization problem:

$$
\max \prod_{i=1}^{n} u_{i}\left(x_{i}\right) \quad \text { subject to } \sum_{i=1}^{n} x_{i} \leq 1, x_{i} \geq 0 \forall i=1, \cdots, n .
$$

Denote the Nash bargaining solution to $\left\langle A, d>\right.$ as $x^{*}=\left(x_{1}^{*}, x_{2}^{*}, \ldots, x_{n}^{*}\right)$. For any subset of players $S \subset N=\{1,2, \ldots, n\}$, let $\left\langle A_{S}, d_{S}>\right.$ be the reduced bargaining problem after removing the players who are not in $S$ and their payoffs in $x^{*}$,

$$
A_{S}=\left\{\left(\left\{u_{i}\left(x_{i}\right)\right\}_{i \in S}\right) \mid \sum_{i \in S} x_{i} \leq 1-\sum_{j \notin S} x_{j}^{*}=\sum_{i \in S} x_{i}^{*}\right\},
$$

and $d_{S}=\left(\left\{u_{i}\left(x_{i}\right)\right\}_{i \in S}\right)=0$. The consistency of the cooperative solution requires that, for any subset $S, x_{S}^{*}=\left(x_{i}^{*}\right)_{i \in S}$ is the cooperative solution in the reduced problem $<A_{S}, d_{S}>{ }^{3}$ The consistency of the Nash bargaining solution implies that the payoff vector of the players who are in $S, x_{S}^{*}$, is the Nash bargaining solution to the reduced bargaining problem $<A_{S}, d_{S}>$,

$$
x_{S}^{*} \in \arg \max \prod_{i \in S} u_{i}\left(x_{i}\right) \quad \text { subject to } \sum_{i \in S} x_{i} \leq 1-\sum_{j \notin S} x_{i}^{*} .
$$

The proof is made straightforward by comparing the first order conditions of (12) and (14). We will utilize the consistency of the Nash bargaining solution to prove our main result.

Proposition 5 Suppose all the players have the same discount factor $\delta$. The unique subgame perfect equilibrium outcome in Proposition 1 converges to the Nash bargaining solution of the corresponding bargaining problem as $\delta$ goes to one.

\footnotetext{
${ }^{3}$ Refer to Lensberg (1988), Lensberg and Thomson (1989) and Thomson (1990 and 1997) for more on the notion of consistency.
} 
Proof: We will prove this proposition by induction. First note that Proposition 5 holds for any two-player game in Binmore (1987). Suppose Proposition 5 holds for any $n$-player game. Next we will show that Proposition 5 holds in any $(n+1)$ player game.

Consider the first bargaining session between players 1 and 2 in a $(n+1)$-player game. Once players 1 and 2 have reached a partial agreement, the equilibrium outcome between the active player (either player 1 or player 2 ) and the remaining $(n-1)$ player will converge to the Nash Bargaining solution to the corresponding bargaining problem. Recall that in any bargaining period during the first session, the proposing player makes an acceptable offer and then bargains with the remaining $(n-1)$ active players. Suppose that in a subgame where player 1 starts the game by making an offer to player 2, the equilibrium outcome is $x=\left(x_{1}, x_{2}, \ldots, x_{n+1}\right)$, and in a subgame where player 2 starts the game by making an offer to player 1 , the equilibrium outcome is $y=\left(y_{1}, y_{2}, \ldots, y_{n+1}\right)$. Condition (6) with $i=1$ and $j=2$ becomes

$$
u_{1}\left(y_{1}\right)=\delta u_{1}\left(x_{1}\right) .
$$

As the common discount factor $\delta$ goes to one, (15) implies that $x_{1}$ and $y_{1}$ have the same limit. Similarly, $x_{2}$ and $y_{2}$ have the same limit as $\delta$ goes to 1 .

Now consider the limits of $x$ and $y$ as $\delta$ goes to 1 . Denote the limits of $x$ and $y$ by $x^{*}$ and $y^{*}$ respectively. As we assumed that Proposition 5 holds in all $n$-player games, we have

$$
\begin{array}{r}
x_{-2}^{*}=\left(x_{1}^{*}, x_{3}^{*}, \ldots, x_{n+1}^{*}\right)=\arg \max u_{1}\left(x_{1}\right) u_{3}\left(x_{3}\right) \ldots u_{n+1}\left(x_{n+1}\right) \\
\text { subject to } x_{1}+x_{3}+\ldots+x_{n+1} \leq 1-x_{2}^{*}, \\
y_{-1}^{*}=\left(y_{2}^{*}, y_{3}^{*}, \ldots, y_{n+1}^{*}\right)=\arg \max u_{2}\left(x_{2}\right) u_{3}\left(x_{3}\right) \ldots u_{n+1}\left(x_{n+1}\right) \\
\text { subject to } x_{2}+x_{3}+\ldots+x_{n+1} \leq 1-y_{1}^{*} .
\end{array}
$$

Since $x_{1}^{*}=y_{1}^{*}$ and $x_{2}^{*}=y_{2}^{*}$, the consistency of the Nash bargaining solution implies that $\left(x_{3}^{*}, \ldots, x_{n}^{*}\right)$ and $\left(y_{3}^{*}, \ldots, y_{n}^{*}\right)$ are the Nash bargaining solutions to the reduced bargaining problems from (16) and (17), respectively. However, since the reduced bargaining problems 
from (16) and (17) under $x_{3}+\ldots x_{n+1} \leq 1-x_{1}^{*}-x_{2}^{*}$ are the same bargaining problem, $\left(x_{3}^{*}, \ldots, x_{n}^{*}\right)$ and $\left(y_{3}^{*}, \ldots, y_{n}^{*}\right)$ represent the same bargaining solution. Indeed, $x$ and $y$ have the same limit as $\delta$ goes to $1, x^{*}=y^{*}$.

To demonstrate that $x^{*}$ is the Nash bargaining solution to the $(n+1)$-player game, we will show that (16) and (17) give the same set of first order conditions as the Nash bargaining solution to the $(n+1)$-player game. Note that the first order conditions to (16) are

$$
u_{1}\left(x_{1}^{*}\right) u_{3}\left(x_{3}^{*}\right) \ldots u_{i}^{\prime}\left(x_{i}^{*}\right) \ldots u_{n+1}\left(x_{n+1}^{*}\right)=C \quad \text { for } i \neq 2
$$

where $C$ is a constant (the multiplier). Multiplying $u_{2}\left(x^{*}\right)$ on both sides of (18), we have

$$
u_{1}\left(x_{1}^{*}\right) u_{2}\left(x_{2}^{*}\right) u_{3}\left(x_{3}^{*}\right) \ldots u_{i}^{\prime}\left(x_{i}^{*}\right) \ldots u_{n+1}\left(x_{n+1}^{*}\right)=C \cdot u_{2}\left(x_{2}^{*}\right) \quad \text { for } i \neq 2 .
$$

Similarly, (17) gives

$$
u_{1}\left(x_{1}^{*}\right) u_{2}\left(x_{2}^{*}\right) u_{3}\left(x_{3}^{*}\right) \ldots u_{i}^{\prime}\left(x_{i}^{*}\right) \ldots u_{n+1}\left(x_{n+1}^{*}\right)=D \cdot u_{1}\left(x_{1}^{*}\right) \quad \text { for } i \neq 1
$$

where $D$ is also a constant. Note that $C \cdot u_{2}\left(x_{2}^{*}\right)=D \cdot u_{1}\left(x_{1}^{*}\right)$ by setting $i \neq 1$ or 2 in (19) and (20). The first order conditions in (19) and (20) imply that

$$
u_{i}^{\prime}\left(x_{i}^{*}\right) u_{j}\left(x_{j}^{*}\right)=u_{i}\left(x_{i}^{*}\right) u_{j}^{\prime}\left(x_{j}^{*}\right), \quad \text { for } i \neq j
$$

Taken together with $x_{1}^{*}+\ldots+x_{n+1}^{*}=1,(21)$ implies that $x^{*}$ is the Nash bargaining solution in the $(n+1)$-player bargaining problem.

Q.E.D.

Similar to Proposition 5, the perfect equilibrium outcome of Proposition 3 also converges to the Nash bargaining solution to the corresponding bargaining problem as players' discount factor goes to one. The proof is very similar to that of Proposition 5, so it is omitted.

Proposition 6 Suppose all players have the same discount factor $\delta$. The unique subgame perfect equilibrium outcome of Proposition 3 converges to the symmetric Nash bargaining solution of the corresponding bargaining problem as $\delta$ goes to one. 
The proofs of Propositions 5 and 6 utilize the consistency of the Nash bargaining solution and the property of the equilibrium in the bilateral bargaining. Consider three player case in either the offer procedure or demand procedure. The second bargaining session is a standard bilateral bargaining game and the unique subgame perfect equilibrium converges to the Nash bargaining solution in the reduced bargaining problem after one player leaves the bargaining. This result implies two curves on the bargaining frontier that describe payoffs to the two players in the second session. One is for players 1 and 3 after player 2 leaves, and the other one is for players 2 and 3 after player 1 leaves, as illustrated in Figure 3. The equilibrium conditions in the first session require that any player receive the same payoff from either leaving or continuing in the limit as $\delta$ goes to one. Therfore, the unique subgame perfect equilibrium must converge to the unique Nash bargaining solution of the corresponding bargaining problem.

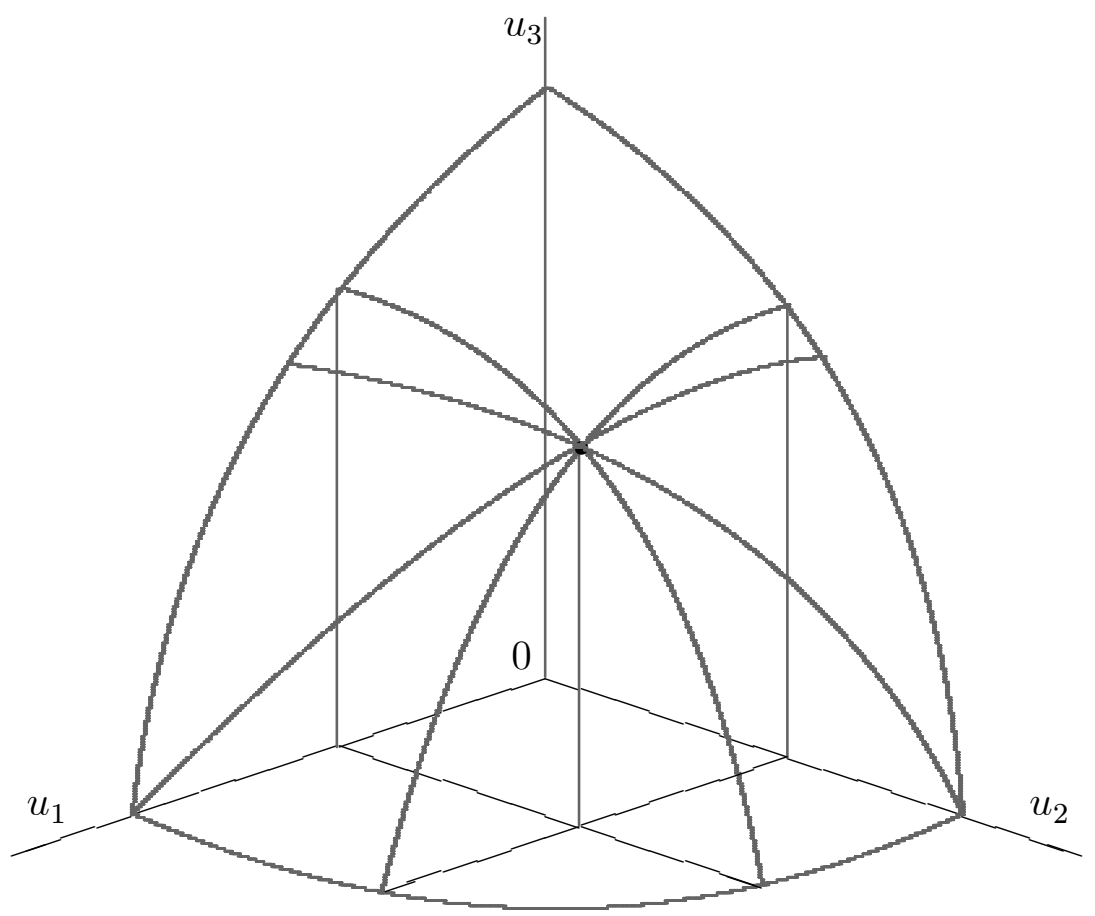

FiguRE 3. Subgame perfect equilibrium and consistency of the Nash bargaining solution. 


\section{Concluding Remarks}

This paper focuses on establishing the linkage between non-cooperative bargaining solutions and the Nash cooperative bargaining solution in a (multi-agent) bilateral bargaining model which is a generalized version of Rubinstein's (1982) bilateral bargaining model. A bilateral bargaining model consists of a finite sequence of bilateral bargaining sessions, and has a unique subgame perfect equilibrium for any given bargaining procedure. We analyze two particular procedures where the subgame perfect equilibrium outcomes converge to the symmetric Nash cooperative bargaining solution in the corresponding bargaining problem as the players' common discount factor goes to one. When players have different discount factors, determined by players' discount rates and the length of each bargaining period, one should be able to show that the subgame perfect equilibrium outcomes in the two cases converge to an asymmetric Nash bargaining solution as the length of each bargaining period shrinks to zero. In the paper, we suggest that a partial agreement in a bargaining session can be thought of as a contingent contract that will be implemented when a full agreement is reached by all the involved players. The player who leaves the game after the partial agreement does not bear any risk or cost of delay since the unique subgame perfect equilibrium in the continuing game is efficient.

The bargaining procedure in this paper is exogenously given. Players do not bargain over their role of being an active bargainer in the coming session or being inactive by exiting the game. Since the shares the players receive depend on this kind of role, it is natural to expect that the players would try to compete over the kind of role which might provide a higher share. Suh and Wen (2003) analyze the bilateral bargaining model with an endogenous bargaining procedure where the proposer makes a proposal of who should exit and who should move on to the next session in addition to proposing how to divide the pie. 


\section{References}

Asheim, G. B. (1992): "A Unique Solution in n-Person Sequential Bargaining," Games and Economic Behavior, 4, 169-181.

Binmore, K. (1987): "Nash Bargaining Solution II," The Economics of Bargaining (Binmore and Dasgupta), Oxford: Blackwell.

Cai, H. (2000): "Delay in Mutilateral Bargaining under Complete Information," Journal of Economic Theory, 93, 260-276.

Chae, S. and J-A. Yang (1994): "An N-person Pure Bargaining Game," Journal of Economic Theory, 62, 86-102.

Chae, S. and J-A. Yang (1990): "An N-Person Bargaining Solution with Alternating Demands," Seoul Journal of Economics, 3, 255-261.

Chae, S. and J-A. Yang (1988): "The Unique Perfect Equilibrium of an N-Person Bargaining Game," Economics Letters, 28, 221-223.

Chatterjee, K. and H. Sabourian (1998): "Multiperson Bargaining and Strategic Complexity," Pennsylvania State University.

Haller, H. (1986): "Non-cooperative Bargaining of $N \geq 3$ Players," Economics Letters, 22, 11-13.

Herrero, M. J. (1985): “N-Player Bargaining and Involuntary Unemployment,” Ph.D. Dissertation, London School of Economics.

Jun, B. H. (1987): "A Strategic Model of 3-Person Bargaining," State University of New York at Stoney Brook.

Krishna, V. and R. Serrano (1996): "Multilateral Bargaining," Review of Economic Studies, $63,61-80$. 
Lensberg, T. (1988): "Stability and the Nash Solution," Journal of Economic Theory, 45, 330-341.

Lensberg, T and W. Thomson (1989): Axiomatic Theory of Bargaining with a Variable Number of Agents, Cambridge University Press.

Muthoo, A. (1999): Bargaining Theory with Applications, Cambridge University Press.

Nash, J. (1950): "The Bargaining Problem," Econometrica, 18, 155-162.

Osborne, M. and A. Rubinstein (1990): Bargaining and Market. Academic Press.

Rubinstein, A (1982): "Perfect Equilibrium in a Bargaining Model," Econometrica, 50, 97-109.

Suh, S. and Q. Wen (2003): "Multi-Agent Bilateral Bargaining with Endogenous Procedures," mimeo, University of Windsor, Vanderbilt University.

Sutton, J. (1986): "Non-cooperative Bargaining Theory: An Introduction," Review of Economic Studies, 53, 709-724.

Shaked, A. and J. Sutton (1984): "Involuntary Unemployment as a Perfect Equilibrium in a Bargaining Model," Econometrica, 52, 1351-1364.

Thomson, W. (1990): "The Consistency Principle," in T. Ichiishi, A. Neyman, and Y. Tauman Eds., Game Theory and Applications, Academic Press.

Thomson, W. (1997): "Consistency and its Converse: an Introduction," University of Rochester. 